\title{
Risk Factors for Prevention Stroke (IS or TIA) Due to Cerebral Infarction in Young Adults: A Meta-Analytical Study
}

\author{
Renardo Lico*, Yanfu Ling, Sandip Kumar Jaiswal \\ Department of Neurology, Zhongda Hospital Affiliated to Southeast University, Nanjing, China \\ Email: *1390826653@qq.com
}

How to cite this paper: Lico, R., Ling, Y.F. and Jaiswal, S.K. (2021) Risk Factors for Prevention Stroke (IS or TIA) Due to Cerebral Infarction in Young Adults: A Meta-Analytical Study. Neuroscience \& Medicine, 12, 62-78.

https://doi.org/10.4236/nm.2021.122006

Received: April 26, 2021

Accepted: June 12, 2021

Published: June 15, 2021

Copyright $\odot 2021$ by author(s) and Scientific Research Publishing Inc. This work is licensed under the Creative Commons Attribution International License (CC BY 4.0).

http://creativecommons.org/licenses/by/4.0/

\begin{abstract}
Ischemic strokes (IS), also referred to as cerebral ischemia or brain ischemia, is a significant cause to the brain cells damage or death. Approximately, $10 \%$ $14 \%$ of ischemic strokes cases occurred in young adults. Hence, we conducted a meta-analysis to find the effective interventions to prevent the best strokes caused by cerebral infarction in young adults. The search was done in different databases, including Google scholar, PubMed, Embase, Medline, Cochrane Central Register of Controlled Trials, Cochrane Database, Scopus, and Web of Science from January 2016 to April 2020, and only English published articles were considered. Our analysis included studies that stratified the risk of ischemic stroke by CHA2DS2-VASc score for patients with nonvalvular atrial fibrillation. Further, random effects model was used to estimate the summary annual rate of IS. Pooled relative risks and odds ratios, with their 95\% confidence intervals, were calculated, respectively. The analysis was conducted using STATA (version 12), pooled effect sizes were calculated using the random-effects model and heterogeneity was tested for using the $P$ statistic. The analysis included 13 studies. The analysis shows that diabetes, high blood pressure, ischemic heart disease, atrial fibrillation, hypercholesterolemia, alcohol consumption and smoking are significant risk factors. In Caucasian and Chinese ischemic stroke patients, the risk factor associations associated with ischemic stroke subtypes are similar. Compared to all other ischemia subtypes, diabetes is more familiar with aortic stroke, atrial fibrillation, ischemic heart disease (with obstruction), hypertension and diabetes. Our research shows that atrial fibrillation, ischemic heart disease, and hypercholesterolemia are low in patients with ischemic stroke and the risk factors are higher. Further analysis of each patient's data is required to enable confounders' adjustments to confirm and expand these findings.
\end{abstract}




\section{Keywords}

Young Adults, Stroke, Cerebral Infarction, Risk-Factors, Prevention

\section{Introduction}

\section{Background}

Ischemic stroke (IS) in young people is far less common than in the elderly, but the potential pathogens and risk factors are more diverse with leading causes of death. Approximately, the prevalence of IS from $10 \%$ to $15 \%$ of all strokes occurs among adults age range 18 to 50 years [1]. The fact is that stroke mimics remain a heterogeneous entity in diagnosis may cause a challenge and difficulty to identify it in young adults.

The latest research revealed the increasing of IS cases among young people in United States and Europe. Increasing of prevalence among younger adults has been documented with an increase in traditional stroke risk factors such as hypertension, dyslipidemia, diabetes mellitus, tobacco use, and obesity which are typically common among older adult's people [2]. On the other hand, young adults were also reported suffering from acute stroke, combined with an increasing of the traditional cardiovascular disease. There is controversy about whether or to what extent these conventional risk factors cause stroke [3] [4], especially for people younger than 40 years old. Evidence shows that stroke is one of leading causes of death among Chinese population, and accounts for about 0.33 of the global death [5]. In addition, the crude death (CDR) in China was sharply increased over the past three decades compared with other countries [6].

Further study published by Strong et al. (2007) reported that 5.7 million deaths due to stroke in year 2005 , and $87 \%$ of these deaths were reported in low-income and middle-income countries [7], thus becoming a global health issue with the increase of the prevalence due to the ageing population, and with the increase of the cases of morbidity and mortality rate [8]. In 2015, China had 15.2 per cent of the population over 60 years of age, and this proportion is expected to rise to 36.5 per cent by 2050 [9]. The evidence shows that among younger stroke patients, there are some risk factors that are either unique to women or more common among women. This includes the use of contraceptive methods that contain estrogenic, pregnancy and migraine auras. Compared to men, migraines and migraines with aura are more common in young women and are more likely to have a stroke while smoking and taking combine oral contraceptives [10]. In addition, a recent previous meta-analysis examined the risk of IS focused on improving risk stratification of ischemic stroke among patients with atrial fibrillation and did not access the possible risk factors for prevention stroke (IS or TIA) due to cerebral infarction in young adults patient. We thus conducted a meta-analysis of all available studies from 2016 to April 2020 to find the effective interventions to prevent the best strokes caused by cerebral 
infarction in young adults. Furthermore, possible moderators such as patients' baseline characteristics and demographic factors including others risk factors associated with adverse IS outcomes were evaluated.

\section{Methodology}

\subsection{Eligibility Criteria}

We included studies that stratified the risk and all articles published in English were assessed in-depth. Overall all titles and abstracts were screened for our inclusion criteria throughout using the Mesh terms (RCT, prospective, placebo controlled study, double-blind, ICAP (double-blind trial, multi-centre), CORP and double-blind, multi-centre, randomized controlled trial pre-documented modern risk factors and stroke prevention (IS and TIA) Cerebral infarction in young people were identifying as inclusion criteria. We also include studies provided scientific reports on risk factors of stroke such as (diabetes, high blood pressure, ischemic heart disease, atrial fibrillation, hypercholesterolemia, alcohol consumption and smoking). We excluded studies that did not meet our criteria such as study that primary data were not available/analyzed (e.g., reviews, editorials, or letters to the editor) or study with lack of standards design, or confusing for the researcher to understand. A total of 2500 studies were reviewed, 100 are screened, 20 full text articles are eligible, and, 13 studies were included in the analysis (Figure 1).

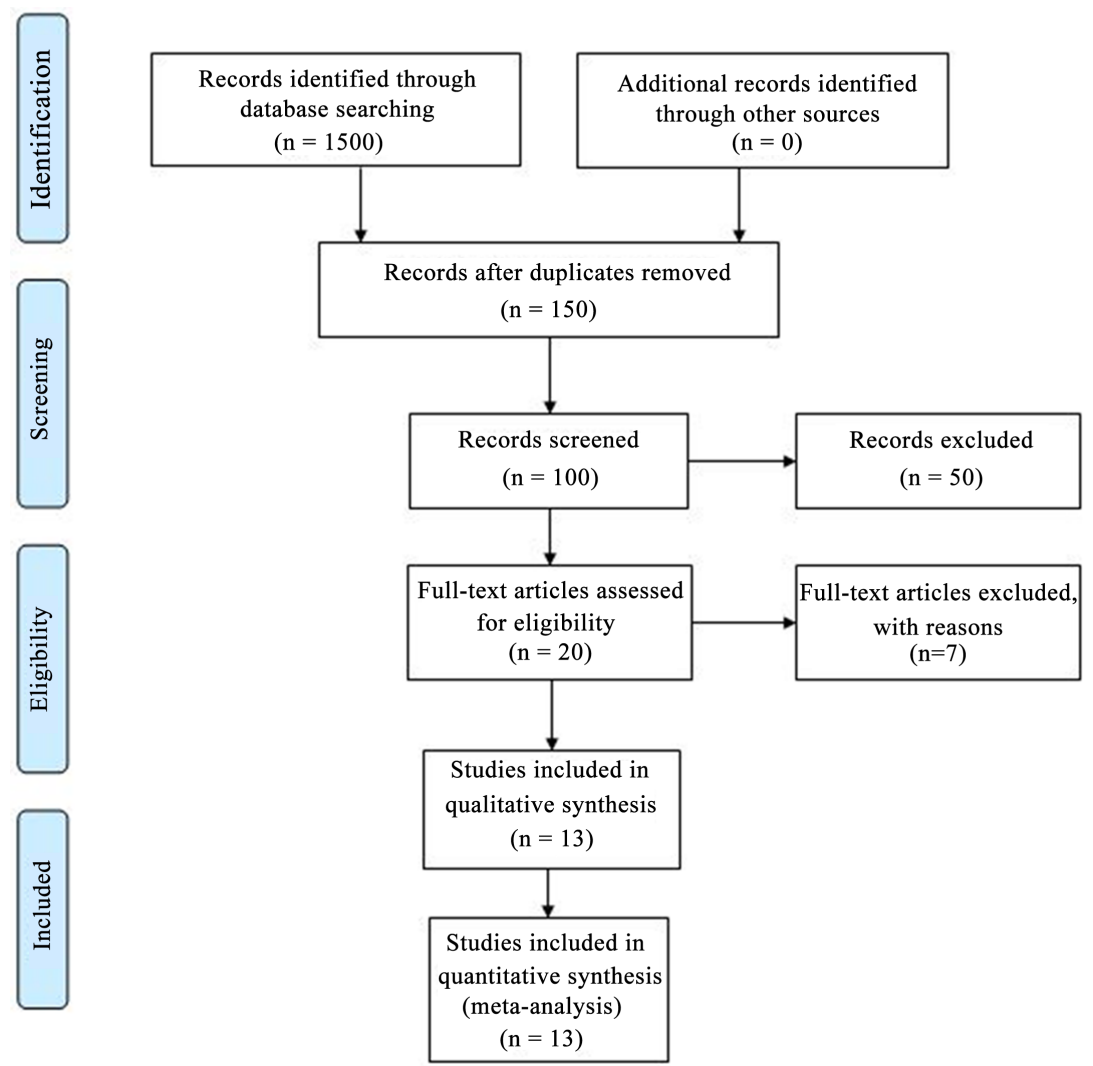

Figure 1. PRISMA flow chart: Search strategy preferred reported items. 


\subsection{Data Sources}

For the purpose of the study, the potential published studies were retrieved based on a literature search of English language articles from 1st January 2016 to April 2020 using Google scholar, PubMed, Embase, Medline, Cochrane Central Register of Controlled Trials, Cochrane Database, Scopus data, and Web of Science using the using keywords "stroke," "cerebral infarction," "risk factors," "prevention", and "young adults,". We also identified pertinent studies through references of the retrieved articles and contacted concerned authors where necessary. Additional relevant publications were identified by a manual search of bibliographies of retrieved studies published above mentioned databases.

\subsection{Study Selection}

We developed standardised data collection. Forms before data collection. Two investigators were extracted data from the overall eligible studies. Then, other co-authors collectively reviewed the extracted data and double check. Finally, all the controlled, randomised trials were included. These (RCT) trials were based on studies in scholarly English medical papers. The selected study followed the recommended guidelines for meta-analysis [11]. The potential published studies were retrieved based on inclusion and exclusion criteria of the study. The overall studies included in the meta-analysis are shown in Table 1.

\subsection{Data Quality and Extraction}

Publishing particulars, integration/outcome measures, demographic trends and cardiac risk ratio of patients registered, interpretation of the intervention strategies was using. Variations of the result and incidents were retrieved and procured. Discussions with the third spectator rectified petty arguments, and then after the discussion, a compromise was managed to reach. Publication bias in RCTs (such as person involved dimness, premature stoppage of the trial for effectiveness before completing scheduled enrollees, and loss to follow-up) was also analysed. The recognised records seemed to be $\mathrm{n}=1500$ via electronic databases. Documentation, consequently recognised from many other references, was $\mathrm{n}=0$. After returned demolition, documents would be included $\mathrm{n}=150$, and the record was then evaluated on the considerations for segregation and integration. The full-text articles were evaluated as per the eligibility requirements, and that was $n=20$. The total number of eight studies $(n=13)$ was deemed (Figure 1).

\subsection{Data Analysis}

The primary data for enrolled studies and number of patients in RCTs and other factors were such as stroke, e.g., Ischemic stroke and Transient Ischemic Attack risk factors and prevention outcome were analysed. All statistical data were analysed using RevMan 5.3 Models of random effects that embed heterogeneity among trials and give broader centrist intervals of confidence (CI) (when heterogeneity prevalent has also been used for all assessments) were discussed. $P$ 
Table 1. Characteristics of the studies included in the meta-analysis.

\begin{tabular}{|c|c|c|c|c|c|c|c|}
\hline $\begin{array}{l}\text { Author Name, } \\
\text { Year }\end{array}$ & $\begin{array}{l}\text { Study } \\
\text { Design }\end{array}$ & Region & $\begin{array}{l}\text { Sample } \\
\text { size }\end{array}$ & $\begin{array}{l}\text { Study } \\
\text { Period }\end{array}$ & $\begin{array}{l}\text { Young Adults } \\
\text { Age range } \\
\text { (Years) }\end{array}$ & Diagnosis & References \\
\hline $\begin{array}{l}\text { Rutten-Jacobs } \\
\quad \text { et al. }\end{array}$ & $\begin{array}{l}\text { FUTURE (Follow-up of transient } \\
\text { ischemic attack and stroke patients and } \\
\text { unelucidated risk factor evaluation) }\end{array}$ & Netherland & 959 & $1980-2010$ & $18-50$ & IS, TIA & [12] \\
\hline $\begin{array}{l}\text { Diaz-Guzman } \\
\text { et al. }\end{array}$ & Spanish IBERICTUS study & Spain & 256 & 2006 & $17-54$ & IS, TIA & [13] \\
\hline Putaala et al. & Cohort & Europe & 3944 & 2010 & $15-49$ & IS & [14] \\
\hline Putaala et al. & Cohort & Finland & 1008 & 2007 & $15-49$ & IS & [15] \\
\hline Toni et al. & $\begin{array}{l}\text { SITS-ISTR (safe implementation } \\
\text { of thrombolysis in stroke-international } \\
\text { stroke thrombolysis register) }\end{array}$ & International & 26,671 & 2012 & $18-50$ & IS & [16] \\
\hline Ji et al. & $\begin{array}{l}\text { Get with the guidelines-stroke } \\
\text { (database at Mass General hospital) }\end{array}$ & Boston, USA & 2643 & 2013 & $15-45$ & IS, TIA & [17] \\
\hline $\begin{array}{l}\text { Greisenegger } \\
\text { et al. }\end{array}$ & Vienna Stroke Registry & Australia & 661 & 2001 & $18<50$ & IS, TIA & [18] \\
\hline Kissela et al. & $\begin{array}{c}\text { Greater Cincinnati/Northern } \\
\text { Kentucky Stroke study (GCNKSS) }\end{array}$ & USA & $\begin{array}{c}1942, \\
2034,1916\end{array}$ & 2005 & $20-54$ & IS & [19] \\
\hline $\begin{array}{c}\text { von } \\
\text { Sarnowski et al. }\end{array}$ & Stroke in Young Fabry Patients cohort & Europe & 4467 & 2010 & $18-55$ & IS, TIA & [20] \\
\hline $\begin{array}{c}\text { Emer R. } \\
\text { McGrath et al. }\end{array}$ & Cohort & Canada & 3197 & 2012 & $20-77$ & IS & [21] \\
\hline $\begin{array}{l}\text { Reetta Kivioja } \\
\quad \text { et al. }\end{array}$ & Case-Control Study & Finland & 961 & 2018 & $25-49$ & IS & [22] \\
\hline $\begin{array}{c}\text { Chirantan } \\
\text { Banerjee et al. }\end{array}$ & Prospective & New York & 3298 & 2012 & $18-66$ & IS & [23] \\
\hline
\end{tabular}

statistics determined statistical heterogeneity $(F=25 \%-49 \%)$, moderate and high. Relative risks (RR) have been used to pool results with a meaning level of 5.0 per cent on two sides. With CIs of 95 per cent, individual trials and description outcomes were also confirmed.

\section{Results and Analysis}

\subsection{A Systematic Review Included Study}

Of the 1500 publications meeting initial search criteria, 20 articles were eligible and 13 detailed articles were finally evaluated and included in the analysis. The meta-analysis considered the ten studies in which FUTURE, RCTs, Cohort, IBERICTUS study, Retrospective, and Prospective were involved. The features of the research findings and factors associated with our meta-analysis were summarized in Table 1 . The study retrieval and selection strategy are illustrated in Figure 1.

\subsection{Baseline Patient's Characteristics}

The participant benchmark attributes have designed to measure the stroke (IS and TIA) in young adults are summarized in Table 2. The studies' considered 
Table 2. Baseline patient's characteristics in ischemic stroke.

\begin{tabular}{|c|c|c|c|c|c|c|}
\hline \multirow{3}{*}{ Variables } & \multicolumn{6}{|c|}{ Baseline Characteristics of Patients with Ischemic Stroke in Young Adults due to Cerebral Infarction } \\
\hline & \multicolumn{6}{|c|}{ Included Studies } \\
\hline & $\begin{array}{c}\text { Andrew } \\
\text { B. Mitchell } \\
\text { et al., } 2015\end{array}$ & $\begin{array}{l}\text { Rutten-Jacobs } \\
\text { LC et al., } 2013\end{array}$ & $\begin{array}{c}\mathrm{Ji} \\
\text { et al., } 2013\end{array}$ & $\begin{array}{c}\text { Toni } \\
\text { et al., } 2012\end{array}$ & $\begin{array}{c}\text { Emer R. } \\
\text { McGrath } \\
\text { et al., } 2012\end{array}$ & $\begin{array}{c}\text { Chirantan } \\
\text { Banerjee et al., } 2012\end{array}$ \\
\hline $\begin{array}{l}\text { Age }(y r s) \\
\text { mean } \pm \text { SD }\end{array}$ & $40.8 \pm 7.1$ & $40.3 \pm 7.8$ & $37.5 \pm 7$ & - & $79.21 \pm 9.81$ & $69 \pm 10$ \\
\hline Male, \% & 52.0 & 47.4 & 38.7 & - & 56.3 & 37.2 \\
\hline Hypertension, \% & 42.3 & 28.1 & 26 & 27.1 & 73.3 & - \\
\hline Diabetes \% & 16.9 & 6.6 & 15 & 5.8 & 24.2 & 36.8 \\
\hline Current Smoker \% & 44.8 & 57.3 & 37 & 42.7 & - & 17.3 \\
\hline $\begin{array}{c}\mathrm{BMI}\left(\mathrm{kg} / \mathrm{m}^{2}\right) \\
\text { mean } \pm \mathrm{SD}\end{array}$ & $29.7 \pm 7.6$ & - & - & - & - & - \\
\hline $\begin{array}{c}\text { Excess Alcohol } \\
\text { Consumption \% }\end{array}$ & - & 7.6 & 1 & - & 7.1 & 32.6 \\
\hline
\end{tabular}

young adults with stroke, and in the previously announced studies. There were studies published of IS and TIA are recorded in Table 2 given the following. Obesity rates in the United States have been gradually rising for many decades. Obesity was prevalent in $16.9 \%$ of youth and 34.9 per cent of adults in the United States in 2011-2012. Obesity is a well-known risk factor for stroke among senior citizens. There is evidence that as young adults' obesity levels rise, their ischemic hospitalisation rates rise as well [2]. Only a few studies have looked into the connection between obesity and early-onset stroke. Characteristics of studies have discussed. According to the survey, it most frequently occurs in $40-69$ years of age as with the highest mean and standard value 79.21 \pm 9.81 . Other details have discussed below.

\subsection{Analysis of Risk Factors for Stroke (IS and TIA) Due to Cerebral Infarction in Young Adults}

Young people now account for nearly half of the worldwide burden of stroke since they can persist stroke for a prolonged period, and stroke happens in countries with poor socio-economic status at a young age [24]. The risk factors, including hypertension, obesity, atrial fibrillation (AF), ischemic stroke (IHD), hyperlipidemia, alcoholism, and cigarette smoking, were investigated. In stroke patients, the prevalence of hypertension is comparable (the combined ratio is 59\%); more details have given in Figure 2.

According to research, the outcomes of ischemic stroke and TIA in young adults were remarkably similar, with insignificant heterogeneity for either risk factor (Figure 3(a)). Diabetes was marginally (ORs 1.34 and 1.42) more 


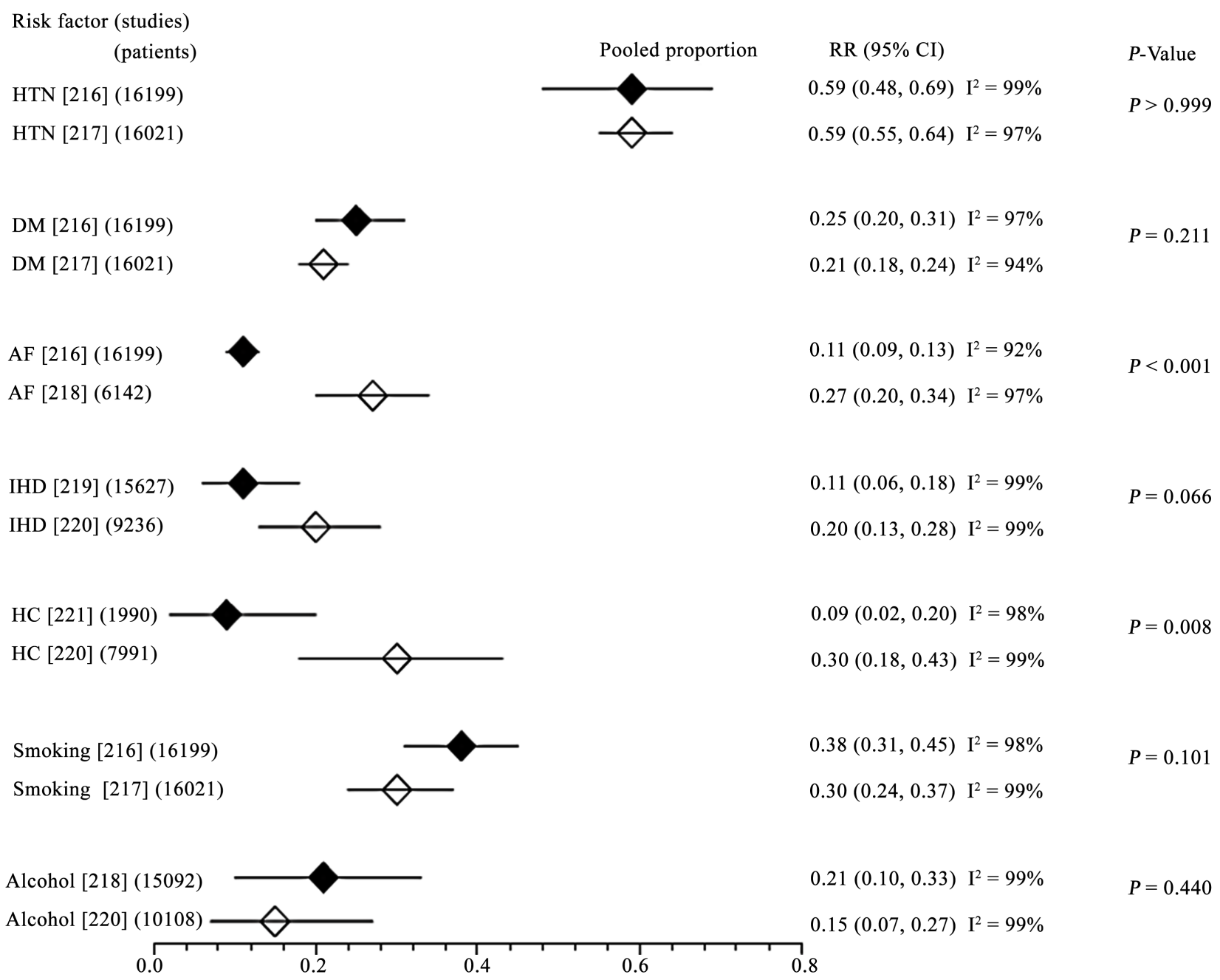

Figure 2. Meta-analysis of the prevalence of risk factors in young patients with ischemic stroke/TIA. $\mathrm{CI}=$ confidence interval; $\mathrm{I}=$ discordance; $\mathrm{HTN}=$ hypertension; DM = diabetes; AF = atrial fibrillation; IHD = ischemic heart disease; HC = hypercholesterolemia. The horizontal line represents $95 \% \mathrm{CI}$ and Percentage of diamonds in total.

common, whereas AF was significantly (ORs 0.27 and 0.19) less common. A meta-analysis of the research from the perspective of China has also conducted. The findings of the study are not always related to race. Compared with white people, Chinese are more likely to drink in IS, but there is no gap between cultural minorities (Figure 3(a)). When comparing IS and TIA strokes, there seems to be an important and powerful positive correlation between atrial fibrillation (the Chinese and white ORs are 71.36 and 36.81, respectively) and IHD (ORs are 3.62 and 1.31). Both were substantially higher in Chinese citizens (Chinese-Caucasian heterogeneity in AF: $P=0.001$, IHD: $P=0.021$; Figure $3(b))$. The CE population and other subtypes have lower rates of hypertension, diabetes, smoking, and drinking. However, the findings of hypertension and diabetes in China, as well as smoking and drinking in Caucasians, are individually important (heterogeneity between hypertension) gender: $P=0.166$, diabetes: $P=$ 0.079, smoking: $P=0.011$, alcohol: $P=0.028$; Figure $3(\mathrm{~b})$ ). 


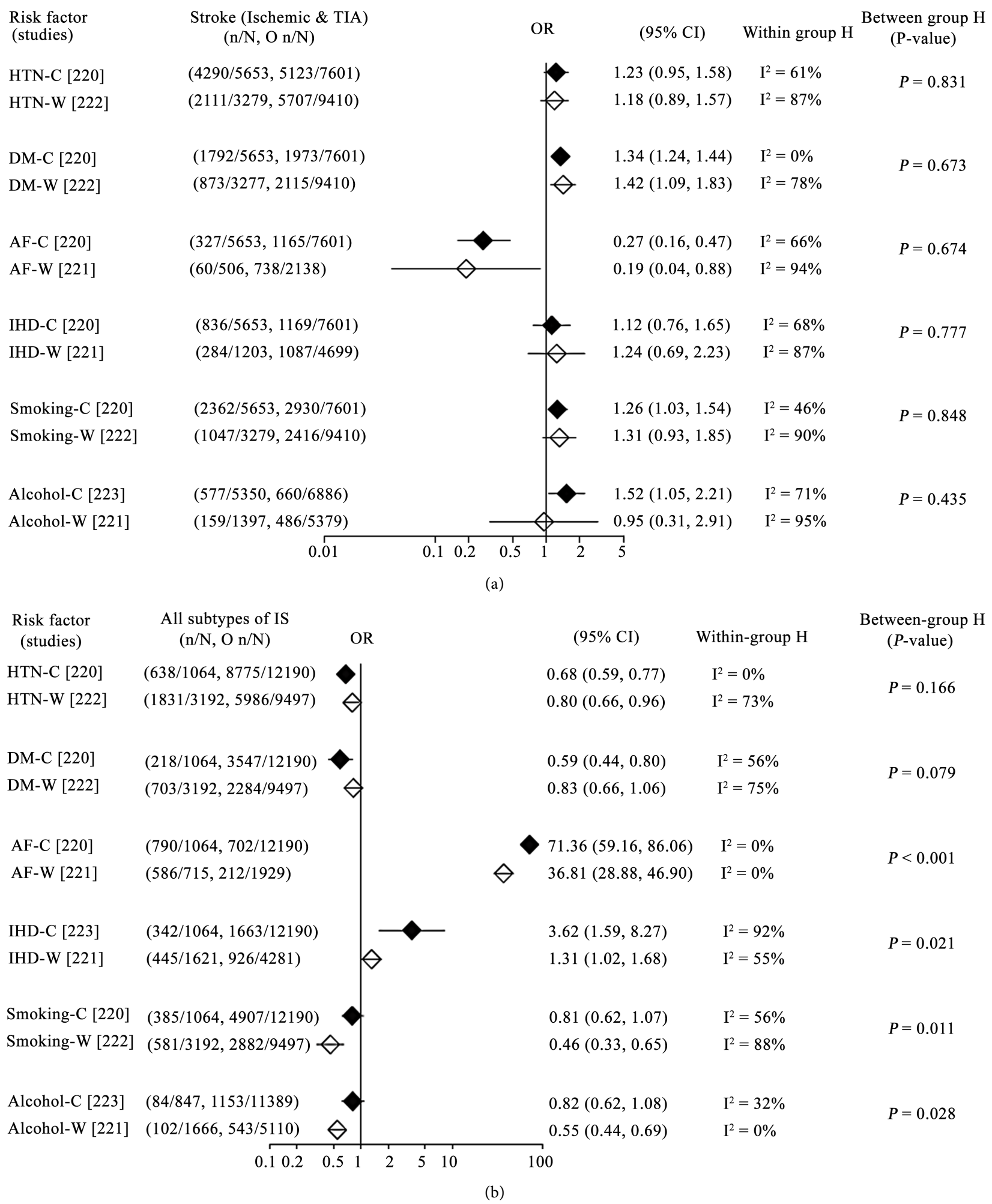

Figure 3. A meta-analysis compares the risk factors (ischemia and TIA) of stroke among young Chinese and Caucasians. (a) The figure shows the odds ratio of the Chinese and Caucasian research on ischemic stroke and TIA risk factors. (b) Shows the risk factors for all subtypes of ischemic stroke. $\mathrm{n}=$ number of patients with risk factors; $\mathrm{N}=$ total number of patients; OR = odds of winning; $\mathrm{CI}=$ confidence interval; $\mathrm{H}=$ heterogeneity; $\mathrm{I}=$ inconsistency; $\mathrm{HTN}=$ hypertension; $\mathrm{DM}=$ diabetes; $\mathrm{IHD}=\mathrm{ischemic}$ heart disease; $\mathrm{C}=$ Chinese; $\mathrm{W}=$ Caucasian (white); the horizontal line represents $95 \% \mathrm{CI}$. The diamond represents the combined operations. 


\subsection{Analysis of Prevention for Stroke (IS and TIA) Due to Cerebral Infarction in Young Adults}

In the current study, RevMan has analysed the prevention of stroke. According to the results of some studies have carried out (Nigel S. Beckett et al., 2008; SHEP Cooperative Research Group, 1991; Lin H et al., 2013; Wang CJ et al., 2016; Zhao J et al., 2015; Yan Y, Zhang X., 2016; and SHEP Cooperative Research Group, 1991) were considered for meta-analysis [22] [23] [25] [26] [27] [28]. More details have discussed in Figure 4.

\section{Discussion}

This meta-analysis aimed at quantifying the risk factors (ischemia and TIA) of stroke, where the findings show an increased BMI is associated with stroke onset, consistent with the study conducted by Meschia JF (2014) in the elderly [29]. After adjusting for hypertension and diabetes, the association between BMI and stroke weakened and was no longer statistically significant. Although the incidence and aetiology of different countries, genders and ethnicities are very different, ischemic stroke in young people can affect people of all races and races. These differences cannot be explained only by the differences in resource-dependent diagnosis and treatment. Comprehending the aetiology of ischemic stroke amongst young adults in numerous countries is crucial for designing regionally effective intervention and prevention strategy to minimise the worldwide stroke risk.

Never the less the findings of the study confirm the incidence of diabetes is slightly higher but much more pronounced (OR 1.34), while AF is significantly less (OR 0.27). Stroke has long associated with hypertension, IHD, and smoking (OR 1.12). Comparing IS and TIA strokes, there is a significant and robust positive correlation between AF and IHD. All are considerably higher in China, while obesity, hypertension, cigarettes, and alcoholism are pretty prevalent in the European population than in other people. The effects of drinking alcohol on

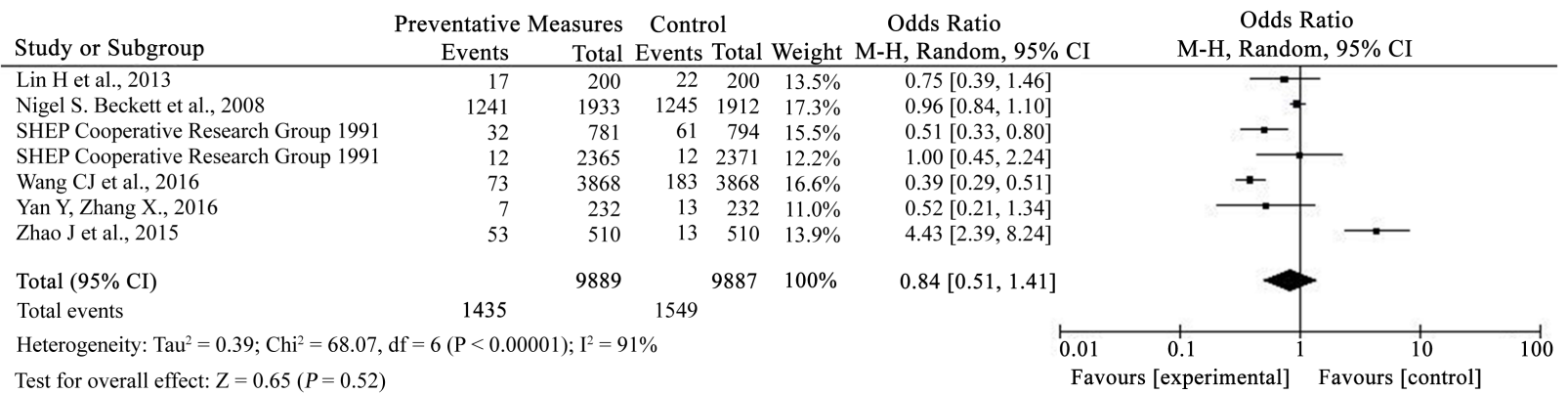

Figure 4. Forest plot of a randomised controlled trial (RCT) of young adults (ischemic stroke and TIA) prevention. The individual and combined odds ratio (OR) of RCT has a 95\% confidence interval (CI). Using the variance component model, the CI OR of $95 \%$ of the combination has calculated. The weights determine the impact of each report on the general calculation of drug effects. Each square and a horizontal line represent the point estimate, and the RR for each trial is $95 \%$ CI. The diamond is the combined OR; the estimated point is the middle of the diamond, and the $95 \% \mathrm{CI}$ is the size. Data from RCT showed an OR of 0.84 . $95 \% \mathrm{CI}$ $0.51-1.41, P=0.52 ; P=91 \%$ of all adverse effects. 
diabetes complications in China and Caucasians are collectively significant (heterogeneity among hypertensive populations). In the current study, In China IS patients, the frequency of AF, IHD, and hyperlipidemia was reduced than in white counterparts and consistent with other reports. Compared with white patients, these risk factors have a higher prevalence in the Chinese population. Because of our meta-analysis, more than $80 \%$ of Chinese IS patients have recruited after 2015. The majority has tripled. Previous studies [30] [31] [32] have given substantial and related interactions in the minority cultural point regarding risk factor associations between ischemic subtypes. Surprisingly, our findings indicate a stronger association between AF and IHD than between IS and TIA.

Patients with diseases of the large arteries or blood vessels are more likely to have dyslipidemia, while stroke caused by cardiac obstruction is less likely to have dyslipidemia. Young dyslipidaemia was not associated with an increased stroke incidence from all causes (PAR $-2.1 \%$; 95\% CI -6.7 to 2.6 , OR $=0.9 ; 95 \%$ CI 0.8 to 1.1). Many other stroke triggers in young adults can also cause this, and dyslipidemia is not always variable.

According to the Fabry Youth Stroke Report (SIFAP), high blood pressure is the most important risk factor for stroke. The PAR is 25.5 per cent (95 percent CI 22.1 to 28.2) and has been associated with stroke in young adults (or: 2.3; 95 per cent). CI 2.0 to 2.6) [20]. Although not a minor stroke, Africa has the highest prevalence of hypertension (46\%), while countries in Latin America have the lowest rate (35\%) [33].

The risk of a stroke due to smoking increases in young people (PAR by $19.9 \%$, $95 \%$ CI from 14.8 to 23.9 , odds ratio $1.78,95 \%$ CI from 1.50 to 2.11 ) [34]. Obesity and inactivity are two configurable risk factors that can contribute to vascular disease. Obesity is characterised by a BMI of 30 or higher and occurs in more than $10 \%$ of young people with stroke [32]. Both developed and developing countries considered obesity as a problem in the middle of the year [35]. Patients with high blood pressure are more likely to have a stroke, which can be reduced by controlling blood pressure. The deposit insurance rate of $30 \%$ to $40 \%$ is associated with blood pressure management following a TIA. The lower your blood pressure, the less likely you are to have a stroke. Reducing sodium intake in the diet and losing weight are significant lifestyle improvements associated with lowering blood pressure. Altered blood pressure values in hypertensive patients could indicate cerebral ischemia and the effects of anti-hypertensive drugs. High systolic blood pressure and maximum variation in systolic blood pressure from a visit to visit were essential predictors of secondary stroke in a group of TIA patients (risk ratios were 6.22 and 15.01, respectively) [20].

Smoking and cerebral ischemia have a dose-response relationship, with heavier smokers being at higher risk. Behaviour therapy is the most effective way to stop smoking. Using a combination of NRT and social support increases your chances of quitting by 50 to 70 per cent [36].

According to studies, the risk of having a stroke within 90 days after a TIA is $10 \%$ to $20 \%$, with half of the stroke occurring [37]. Treatment, including drug 
therapy and surgery, should begin as soon as possible after a TIA to reduce the risk of stroke. This could mean that patients at high risk would benefit from hospitalisation. The possibility of comprehensive medical testing, diagnosis, and early care to reduce stroke risk is one of the benefits of inclusion. If a patient has a stroke in the hospital, the use of TPA could be improved. It should be used on any patient with lesions on an MRI scan. TIA and TIA control can help reduce the risk of a later stroke. In the first evaluation, 50 to 80 per cent of patients with a TIA or moderate stroke had high blood pressure [38]. According to the TIA, patients with systolic blood pressure greater than $140 \mathrm{~mm} \mathrm{Hg}$ or diastolic blood pressure greater than $90 \mathrm{~mm} \mathrm{Hg}$ have a higher risk of stroke (odds ratio $=2.1$, 1.9 , and 1.6 at days 2,7 , and 90, respectively). Comorbidities, age and risk of hypotension should be considered when lowering blood pressure [39].

Antiplatelet drugs have been prescribed to patients with non-thromboembolic cardiac TIA or a stroke history to prevent further stroke. According to AHA/ASA guidelines, aspirin and dipyridamole/aspirin (Aggrenox), and clopidogrel (Plavix) are appropriate guidelines for first-line AHA/ASA medications. Aspirin is the most widely used platelet aggregation inhibitor and has been shown to reduce stroke risk in humans [40]. The European Stroke Prevention Study 2 compared the stroke prevention effects of aspirin and dipyridamole (Persantine) and their combinations. The incidence of moderate wind was $18 \%$ after patients with a TIA history or stroke received aspirin therapy, and the resulting TIA was $22 \%$. The optimal dose of aspirin for efficacy and protection is 81 milligrams per day [40]. Various reports indicate that adding dipyridamole extended-release to aspirin can reduce the frequency of ischemic brain events, including the European Stroke Prevention Study 2. The actual risk is reduced by 5.9\% (number of treatments $=17$ ) compared to placebo. Compared to aspirin alone, the ESPRIT (European/Australian Reverse Stroke Prevention Trial) study with dipyridamole/aspirin showed that the absolute risk of stroke was reduced by another $1 \%$ per year [41]. According to the META analysis, the average requirement for dipyridamole/aspirin was $23 \%$ compared to aspirin and $37 \%$ compared to placebo.

In the PRoFESS non-inferiority study (the prevention program to successfully prevent the second stroke), clopidogrel was compared with presentation/aspirin in subjects diagnosed with stroke [42]. Clopidogrel was compared with aspirin with clopidogrel alone in the MATCH study (clopidogrel treatment for arterial thrombosis in high-risk patients) to prevent stroke after a transient ischemic attack or previous stroke. This combination increased the risk of bleeding and reduced the risk of statistically significant vascular events. Because anticonvulsant agents are used to preventing stroke after a TIA is similar, drugs should be selected based on the risk and clinical condition of the patient, cost factors, and side effects. Due to bleeding risk, taking clopidogrel with aspirin is not recommended to avoid stroke unless there are other indications for treatment [43].

According to the AHA/ASA, patients with chronic coronary artery disease and hypertensive patients at high risk of developing cardiovascular disease should take a statin to avoid stroke, regardless of their initial LDL-C levels, 
according to the AHA/ASA. Prescription statins for patients who have previously had a TIA or stroke but were not suspected of having coronary artery disease and who have LDL-C levels greater than $100 \mathrm{mg} / \mathrm{dL}$ (2.59 mmol/L). The LDL-C level must be reduced by at least $50 \%$, or the target value must be less than 70 $\mathrm{mg} / \mathrm{dL}(1.81 \mathrm{mmol} / \mathrm{L})$ [44]. Statin treatment reduces the overall risk of a five-year stroke in patients with a TIA or history of stroke by 2.2 per cent (response ratio to 16 per cent; the number of treatments required $=45$ ). Compared with ischemic stroke, LDL-C levels are reduced by $50 \%$ or more, LDL-C levels are increased by $33 \%$, and significant coronary events are reduced by $37 \%$. [44] Statin therapy reduces the risk of clinically significant CHD for five years from $8.6 \%$ to $5.1 \%$ in patients with a history of TIA or stroke who are not known to have $\mathrm{CHD}$ (overall risk limit $=3.5 \%$ ); (people treated $=29$ ) [45]. Patients with a TIA or stroke are said to have an asymptomatic disease. The EVA-3S test (endarterectomy and angioplasty in patients with severe carotid stenosis) found a 3.9 per cent chance of signs or symptoms by day 30 of stroke or death. The incidence of complications after surgery was $9.6 \%$. After six months, the risk of stroke or death due to carotid endarterectomy was $6.1 \%$, and stroke or death due to carotid endarterectomy was $11.7 \%$ [46]. The risk of stroke or death for four years after carotid endarterectomy was $4.7 \%$, and the risk for four years after fixation of the carotid artery stencil was $6.4 \%$. However, myocardial infarction is more common after carotid endarterectomy [47]. If the incidence of stenosis is less than $50 \%$, then no intervention is required. In some cases, carotid tentacle may be considered (e.g., if entry into the restricted area during surgery is complicated, and the risk of complications from endovascular interventions is low) [48]. The current study included metadata of a number of stroke prevention reports. Our results show that anti-hypertensive drugs, statins, exercise and smoking cessation are the most important preventative measures to prevent stroke. Our analysis has some major strengths. First, we will perform a thorough search to find any relevant search published in English. Second, we only included studies that used widely accepted stroke concepts, classified approaches, risks, and preventive measures. Third, we carefully recorded the characteristics, processes, and concepts of the risk factors used in each specific analysis. There are some limitations. According to a systematic search in the literature, only a few studies meet the requirements for inclusion. Clinic-based studies have only found that the ideal research population is community-based and covers all stroke patients in a specific setting. Second, we do not have patient personal data corrected for potential confusing variables (such as age) and socio-economic and educational data that could be used for interpretation, as our research focused on publicly available data.

\section{Conclusion}

Because of the rising incidence and long-term effects of stroke among young adults, all developed and developing countries will face severe public health concerns. Geographical, racial, and sex variations and susceptibility to vascular 
complications all contribute to the significant disparities in the prevalence of ischemic stroke between young adults seen worldwide. With the increase in risk factors worldwide, ideally, in all income types of countries, the focus should be on primary and secondary prevention from the beginning. Attention should pay to the risk factors for specific continents and specific countries. The conclusion is that given that stroke is a frequent and severe disease, stroke prevention is a vital issue, and effective acute stroke therapy at the individual level has limited public health impact. Vascular risk factors such as high blood pressure, hyperlipidemia, and smoking should address from stroke prevention. The best treatment of stroke risk factors for all stroke and TIA cases and antithrombotic therapy and carotid artery surgery for patients with severe ischemic stroke or TIA are the supplementary strategies for reducing the risk of any new incidents following the first ischemic stroke or TIA.

\section{Conflicts of Interest}

The authors declare no conflicts of interest regarding the publication of this paper.

\section{References}

[1] Singhal, A.B., Biller, J., Elkind, M.S., Fullerton, H.J., Jauch, E.C., Kittner, S.J. and Levine, S.R. (2013) Recognition and Management of Stroke in Young Adults and Adolescents. Neurology, 81, 1089-1097. https://doi.org/10.1212/WNL.0b013e3182a4a451

[2] George, M.G., Tong, X. and Bowman, B.A. (2017) Prevalence of Cardiovascular Risk Factors and Strokes in Younger Adults. JAMA Neurology, 74, 695-703. https://doi.org/10.1001/jamaneurol.2017.0020

[3] Putaala, J. (2016) Ischemic Stroke in the Young: Current Perspectives on Incidence, Risk Factors, and Cardiovascular Prognosis. European Stroke Journal, 1, 28-40. https://doi.org/10.1177/2396987316629860

[4] Aigner, A., Grittner, U., Rolfs, A., Norrving, B., Siegerink, B. and Busch, M.A. (2017) Contribution of Established Stroke Risk Factors to the Burden of Stroke in Young Adults. Stroke, 48, 1744-1751. https://doi.org/10.1161/STROKEAHA.117.016599

[5] Rosengren, A., Giang, K.W., Lappas, G., Jern, C., Torén, K. and Björck, L. (2013) Twenty-Four-Year Trends in the Incidence of Ischemic Stroke in Sweden from 1987 to 2010. Stroke, 44, 2388-2393. https://doi.org/10.1161/STROKEAHA.113.001170

[6] Wu, S., Wu, B., Liu, M., Chen, Z., Wang, W., Anderson, C.S., Zhang, S., et al. (2019) Stroke in China: Advances and Challenges in Epidemiology, Prevention, and Management. The Lancet Neurology, 18, 394-405. https://doi.org/10.1016/S1474-4422(18)30500-3

[7] Strong, K., Mathers, C. and Bonita, R. (2007) Preventing Stroke: Saving Lives around the World. The Lancet Neurology, 6, 182-187. https://doi.org/10.1016/S1474-4422(07)70031-5

[8] Du, S., Mroz, T.A., Zhai, F. and Popkin, B.M. (2004) Rapid Income Growth Adversely Affects Diet Quality in China-Particularly for the Poor! Social Science \& Medicine, 59, 1505-1515. https://doi.org/10.1016/j.socscimed.2004.01.021 
[9] Gaziano, T.A., Bitton, A., Anand, S., Abrahams-Gessel, S. and Murphy, A. (2010) Growing Epidemic of Coronary Heart Disease in Low- and Middle-Income Countries. Current Problems in Cardiology, 35, 72-115. https://doi.org/10.1016/j.cpcardiol.2009.10.002

[10] Tietjen, G.E. and Maly, E.F. (2020) Migraine and Ischemic Stroke in Women. A Narrative Review. Headache: The Journal of Head and Face Pain, 60, 843-863. https://doi.org/10.1111/head.13796

[11] Wolfe, C.D. (2000) The Impact of Stroke. British Medical Bulletin, 56, 275-286. https://doi.org/10.1258/0007142001903120

[12] Caplan, L.R. (2016) Caplan's Stroke. Cambridge University Press, Cambridge. https://doi.org/10.1017/CBO9781316095805

[13] Díaz-Guzmán, J., Egido, J.A., Gabriel-Sánchez, R., Barberá-Comes, G., Fuentes-Gimeno, B. and Fernández-Pérez, C. (2012) Stroke and Transient Ischemic Attack Incidence Rate in Spain: The IBERICTUS Study. Cerebrovascular Diseases, 34, 272-281. https://doi.org/10.1159/000342652

[14] Rutten-Jacobs, L.C., Maaijwee, N.A., Arntz, R.M., Schoonderwaldt, H.C., Dorresteijn, L.D., van Dijk, E.J. and de Leeuw, F.E. (2014) Clinical Characteristics and Outcome of Intracerebral Hemorrhage in Young Adults. Journal of Neurology, 261, 2143-2149. https://doi.org/10.1007/s00415-014-7469-6

[15] Putaala, J., Yesilot, N., Waje-Andreassen, U., Pitkäniemi, J., Vassilopoulou, S., Nardi, K., Tatlisumak, T., et al. (2012) Demographic and Geographic Vascular Risk Factor Differences in European Young Adults with Ischemic Stroke: The 15 Cities Young Stroke Study. Stroke, 43, 2624-2630. https://doi.org/10.1161/STROKEAHA.112.662866

[16] Toni, D., Ahmed, N., Anzini, A., Lorenzano, S., Brozman, M., Kaste, M. and SITS Investigators (2012) Intravenous Thrombolysis in Young Stroke Patients: Results from the SITS-ISTR. Neurology, 78, 880-887. https://doi.org/10.1212/WNL.0b013e31824d966b

[17] Ji, R., Schwamm, L.H., Pervez, M.A. and Singhal, A.B. (2013) Ischemic Stroke and Transient Ischemic Attack in Young Adults: Risk Factors, Diagnostic Yield, Neuroimaging, and Thrombolysis. JAMA Neurology, 70, 51-57.

https://doi.org/10.1001/jamaneurol.2013.575

[18] Greisenegger, S., Zehetmayer, S., Ferrari, J., Lang, W., Fizek, J., Auff, E., Serles, W. et al. (2011) Clinical Predictors of Death in Young and Middle-Aged Patients with Ischemic Stroke or Transient Ischemic Attack: Long-Term Results of the Vienna Stroke Registry. Journal of Neurology, 258, 1105-1113. https://doi.org/10.1007/s00415-010-5893-9

[19] Kissela, B.M., Khoury, J.C., Alwell, K., Moomaw, C.J., Woo, D., Adeoye, O., Kleindorfer, D.O., et al. (2012) Age at Stroke: Temporal Trends in Stroke Incidence in a Large, Biracial Population. Neurology, 79, 1781-1787. https://doi.org/10.1212/WNL.0b013e318270401d

[20] von Sarnowski, B., Putaala, J., Grittner, U., Gaertner, B., Schminke, U., Curtze, S., Tatlisumak, T., et al. (2013) Lifestyle Risk Factors for Ischemic Stroke and Transient Ischemic Attack in Young Adults in the Stroke in Young Fabry Patients Study. Stroke, 44, 119-125. https://doi.org/10.1161/STROKEAHA.112.665190

[21] McGrath, E.R., Kapral, M.K., Fang, J., Eikelboom, J.W., O’Conghaile, A., Canavan, M. and Investigators of the Ontario Stroke Registry (2013) Association of Atrial Fibrillation with Mortality and Disability after Ischemic Stroke. Neurology, 81, 825-832. https://doi.org/10.1212/WNL.0b013e3182a2cc15 
[22] Peters, R., Martin-Marero, C., Pinto, E. and Beckett, N. (2007) Hypertension in the very Elderly. Aging Health, 3. https://doi.org/10.2217/1745509X.3.4.517

[23] Kawahara, Y., de la Bastide, M., Hamilton, J.P., Kanamori, H., McCombie, W.R., Ouyang, S., Matsumoto, T., et al. (2013) Improvement of the Oryza sativa Nipponbare Reference Genome Using Next Generation Sequence and Optical Map Data. Rice, 6, 1-10. https://doi.org/10.1186/1939-8433-6-4

[24] Vangen-Lønne, A.M., Wilsgaard, T., Johnsen, S.H., Carlsson, M. and Mathiesen, E.B. (2015) Time Trends in Incidence and Case Fatality of Ischemic Stroke: The Tromsø Study 1977-2010. Stroke, 46, 1173-1179. https://doi.org/10.1161/STROKEAHA.114.008387

[25] Wang, Z., Lu, Y., Yan, Y., Larissa, T.Y.P., Zhang, X., Wuu, D., Wang, X., et al. (2016) Core-Shell Carbon Materials Derived from Metal-Organic Frameworks as an Efficient Oxygen Bifunctional Electrocatalyst. Nano Energy, 30, 368-378. https://doi.org/10.1016/j.nanoen.2016.10.017

[26] Zhao, J., Mou, Y., Bernstock, J.D., Klimanis, D., Wang, S., Spatz, M., Hallenbeck, J.M., et al. (2015) Synthetic Oligodeoxynucleotides Containing Multiple Telemeric TTAGGG Motifs Suppress Inflammasome Activity in Macrophages Subjected to Oxygen and Glucose Deprivation and Reduce Ischemic Brain Injury in Stroke-Prone Spontaneously Hypertensive Rats. PLoS ONE, 10, e0140772.

https://doi.org/10.1371/journal.pone.0140772

[27] Yan, Y., Jiang, K., Liu, P., Zhang, X., Dong, X., Gao, J. and Gong, P. (2016) Bafilomycin A1 Induces Caspase-Independent Cell Death in Hepatocellular Carcinoma Cells via Targeting of Autophagy and MAPK Pathways. Scientific Reports, 6, Article No. 37052. https://doi.org/10.1038/srep37052

[28] Shep, C.R.G. and Collaborative Research Group (1991) Prevention of Stroke by Antihypertensive Drug Treatment in Older Persons with Isolated Systolic Hypertension. Final Results of the Systolic Hypertension in the Elderly Program (SHEP). JAMA, 265, 3255-3264. https://doi.org/10.1001/jama.265.24.3255

[29] Meschia, J.F., Bushnell, C., Boden-Albala, B., Braun, L.T., Bravata, D.M., Chaturvedi, S. and Wilson, J.A. (2014) Guidelines for the Primary Prevention of Stroke: A Statement for Healthcare Professionals from the American Heart Association/American Stroke Association. Stroke, 45, 3754-3832. https://doi.org/10.1161/STR.0000000000000046

[30] Mantel, N. and Haenszel, W. (1959) Statistical Aspects of the Analysis of Data from Retrospective Studies of Disease. Journal of the National Cancer Institute, 22, 719-748.

[31] Borenstein, M., Hedges, L.V., Higgins, J.P. and Rothstein, H.R. (2011) Introduction to Meta-Analysis. John Wiley \& Sons, Hoboken.

[32] Orwin, R.G. and Boruch, R.F. (1982) RRT Meets RDD: Statistical Strategies for Assuring Response Privacy in Telephone Surveys. Public Opinion Quarterly, 46, 560-571. https://doi.org/10.1086/268752

[33] Esnault, P., Cardinale, M., Boret, H., D’Aranda, E., Montcriol, A., Bordes, J., Meaudre, E., et al. (2016) Blunt Cerebrovascular Injuries in Severe Traumatic Brain Injury: Incidence, Risk Factors, and Evolution. Journal of Neurosurgery, 127, 16-22. https://doi.org/10.3171/2016.4.JNS152600

[34] Markidan, J., Cole, J.W., Cronin, C.A., Merino, J.G., Phipps, M.S., Wozniak, M.A. and Kittner, S.J. (2018) Smoking and Risk of Ischemic Stroke in Young Men. Stroke, 49, 1276-1278. https://doi.org/10.1161/STROKEAHA.117.018859

[35] Putaala, J., Metso, A.J., Metso, T.M., Konkola, N., Kraemer, Y., Haapaniemi, E., 
Tatlisumak, T., et al. (2009) Analysis of 1008 Consecutive Patients Aged 15 to 49 with First-Ever Ischemic Stroke: The Helsinki Young Stroke Registry. Stroke, 40, 1195-1203. https://doi.org/10.1161/STROKEAHA.108.529883

[36] Arai, D., Satow, T., Komuro, T., Kobayashi, A., Nagata, H. and Miyamoto, S. (2016) Evaluation of the Arterial Wall in Vertebrobasilar Artery Dissection Using High-Resolution Magnetic Resonance Vessel Wall Imaging. Journal of Stroke and Cerebrovascular Diseases, 25, 1444-1450. https://doi.org/10.1016/j.jstrokecerebrovasdis.2016.01.047

[37] Vemmos, K.N., Bots, M.L., Tsibouris, P.K., Zis, V.P., Grobbee, D.E., Stranjalis, G.S. and Stamatelopoulos, S. (1999) Stroke Incidence and Case Fatality in Southern Greece: The Arcadia Stroke Registry. Stroke, 30, 363-370.

https://doi.org/10.1161/01.STR.30.2.363

[38] Tsiskaridze, A., Djibuti, M., Van Melle, G., Lomidze, G., Apridonidze, S., Gauarashvili, I. and Bogousslavsky, J. (2004) Stroke Incidence and 30-Day Case-Fatality in a Suburb of Tbilisi: Results of the First Prospective Population-Based Study in Georgia. Stroke, 35, 2523-2528. https://doi.org/10.1161/01.STR.0000144683.96048.98

[39] Goldstein, L.B., Adams, R., Alberts, M.J., Appel, L.J., Brass, L.M., Bushnell, C.D., Sacco, R.L., et al. (2006) Primary Prevention of Ischemic Stroke: A Guideline from the American Heart Association/American Stroke Association Stroke Council: Cosponsored by the Atherosclerotic Peripheral Vascular Disease Interdisciplinary Working Group; Cardiovascular Nursing Council; Clinical Cardiology Council; Nutrition, Physical Activity, and Metabolism Council; and the Quality of Care and Outcomes Research Interdisciplinary Working Group: The American Academy of Neurology Affirms the Value of This Guideline. Stroke, 37, 1583-1633. https://doi.org/10.1161/01.STR.0000223048.70103.F1

[40] O'donnell, M.J., Xavier, D., Liu, L., Zhang, H., Chin, S.L., Rao-Melacini, P. and Yusuf, S. (2010) Risk Factors for Ischaemic and Intracerebral Haemorrhagic Stroke in 22 Countries (the INTERSTROKE Study): A Case-Control Study. The Lancet, 376, 112-123. https://doi.org/10.1016/S0140-6736(10)60834-3

[41] Amarenco, P., Goldstein, L.B., Szarek, M., Sillesen, H., Rudolph, A.E., Callahan III, A. and Welch, K.M.A. (2007) Effects of Intense Low-Density Lipoprotein Cholesterol Reduction in Patients with Stroke or Transient Ischemic Attack: The Stroke Prevention by Aggressive Reduction in Cholesterol Levels (SPARCL) Trial. Stroke, 38, 3198-3204. https://doi.org/10.1161/STROKEAHA.107.493106]

[42] Rothwell, P.M., Howard, S.C., Dolan, E., O’Brien, E., Dobson, J.E., Dahlöf, B., Poulter, N.R., et al. (2010) Prognostic Significance of Visit-to-Visit Variability, Maximum Systolic Blood Pressure, and Episodic Hypertension. The Lancet, 375, 895-905. https://doi.org/10.1016/S0140-6736(10)60308-X

[43] Wannamethee, S.G., Shaper, A.G., Whincup, P.H. and Walker, M. (1995) Smoking Cessation and the Risk of Stroke in Middle-Aged Men. JAMA, 274, 155-160. https://doi.org/10.1001/jama.1995.03530020073035

[44] Rigotti, N.A. (2012) Strategies to Help a Smoker Who Is Struggling to Quit. JAMA, 308, 1573-1580. https://doi.org/10.1001/jama.2012.13043

[45] Moore, T.J., Furberg, C.D., Glenmullen, J., Maltsberger, J.T. and Singh, S. (2011) Suicidal Behavior and Depression in Smoking Cessation Treatments. PLoS ONE, 6, e27016. https://doi.org/10.1371/journal.pone.0027016

[46] Skyler, J.S., Bergenstal, R., Bonow, R.O., Buse, J., Deedwania, P., Gale, E.A., Sherwin, R.S., et al. (2009) Intensive Glycemic Control and the Prevention of Cardiovascular Events: Implications of the ACCORD, ADVANCE, and VA Diabetes Tri- 
als: A Position Statement of the American Diabetes Association and a Scientific Statement of the American College of Cardiology Foundation and the American Heart Association. Journal of the American College of Cardiology, 53, 298-304. https://doi.org/10.1016/j.jacc.2008.10.008

[47] Ebrahim, S., Sung, J., Song, Y.M., Ferrer, R.L., Lawlor, D.A. and Smith, G.D. (2006) Serum Cholesterol, Haemorrhagic Stroke, Ischaemic Stroke, and Myocardial Infarction: Korean National Health System Prospective Cohort Study. BMJ, 333, 22. https://doi.org/10.1136/bmj.38855.610324.80

[48] Simmons, B.B., Gadegbeku, A.B. and Cirignano, B. (2012) Transient Ischemic Attack: Part II. Risk Factor Modification and Treatment. American Family Physician, 86, 527-532. 